P. H. ESSER (Chairman)

\title{
FINAL SPEECH
}

\section{Ladies en Gentlemen!}

At the closing of this Conference I wish to express my cordial thanks to all of you, not only to those performers among you who have read a paper, but also to the audience, it being not always such a simple task to be the hearer to rather complicated statements about Information Theories. We all will agree that the way in which these theories were explained to us was most interesting. Once again we were impressed by the fact that isolation of certain sorts of observation from others can be an enormous help. So studies of the neurons have been of the greatest value because they have shown us a great deal about the way the nervous system works by transmitting information. New analogies have been found to describe certain processes going on in the human organism. Models have in science been made which give an insight into some aspects of these processes. Everywhere there seems to be a tendency to come to a more exact way of describing biological and sociological phenomena.

In the course of this conference you have been able to contact several prominent scientists in the field of Information Theory. We once again express the hope that in future time we will come to a closer cooperation with the representatives of important groups of scientists outside Holland and that this co-operation will contribute to a clarification of the concepts under investigation. And with this in mind we take leave of you, hoping to meet you again at next year's Summer Conference. 